\title{
Topologi Sarang Orangutan Tapanuli (Pongo tapanuiliensis) di Hutan Batang Toru Kecamatan Sipirok Tapanuli Selatan
}

\author{
Apriani Sijabat ${ }^{(1)}$, Herna Febrianty Sianipar ${ }^{(2)}$, Ady Frenly Simanullang (3) \\ Universitas HKBP Nomensen Pematang Siantar ${ }^{(1)(2)(3)}$ \\ aprianisijabat@gmail.com, hernasianipar54@gmail.com, adyfrenly@gmail.com
}

\begin{abstract}
ABSTRAK
Penelitian ini bertujuan untuk mengetahui keragaman tanaman penyusun sarang orangutan Tapanuli (Pongo tapanuiliensis), mengetahui jenis tanaman yang paling dominan oleh orangutan Tapanuli (Pongo tapanuiliensis) untuk menyusun sarang, mengetahui komposisi penyusun sarang orangutan Tapanuli di Besitang. Penelitian ini dilakukan di hutan Batang Toru Penelitian ini menggunakan metode line transek dengan 4 Jalur transek (transek I,II,III,IV) yang digunakan untuk mengamati pohon sarang dan penyusun sarang orangutan Tapanuli. Hasil penelitian ini adalah ada 6 spesies tumbuhan yang digunakan sebagai tanaman penyusun sarang dengan jumlah 14 sarang. Tanaman penyusun sarang sarang yang paling dominan adalah Hayun Dolok (Syzygium sp) 43\%, Medang (Litsea brachystachys) 29\%, Mayang (Palaquium gutta) 14\%, Laccat bodat (Shorea hopeifolia) $7 \%$ dan Hoteng (Quercus gemelliflora) $7 \%$.
\end{abstract}

Kata Kunci : Sarang, Orangutan, Tapanuli

\begin{abstract}
This research is aimed to know the variety of constituents plant the nests of Tapanuli orangutan (Pongo tapanuiliensis), to know the kind of the most dominant plant to construct the nests by Tapanuli orangutan (Pongo tapanuiliensis), the composition of constituents the nests of sumatran orangutan (Pongo abelli) in Besitang. This research was conducted in Batang Toru forest. This research using line transect method with 4 transects (transects I, II, III, IV) were used to observe the nest tree and the nest constituent of Tapanuli orangutan. This research results is there are 6 species of of constituents plant the nests with quantity 14 nests. The most dominant tree nest is Hayun Dolok (Syzygium sp) 43\%, Medang (Litsea brachystachys) 29\%, Mayang (Palaquium gutta) 14\%, Laccat bodat (Shorea hopeifolia) 7\% dan Hoteng (Quercus gemelliflora) 7\%.
\end{abstract}

Keywords: Nest, Orangutans, Tapanuli 
Sijabat A, Sianipar Herna F, Simanullang Ady F : Topologi Sarang Orangutan Tapanuli (Pongo tapanuiliensis) di Hutan Batang Toru Kecamatan Sipirok Tapanuli Selatan

\section{PENDAHULUAN}

\section{Latar Belakang}

Orangutan merupakan satu-satunya spesies kera Asia yang masih hidup. Hal ini membuat orangutan menjadi salah satu hewan yang dilindungi baik secara spesies maupun habitatnya yang semakin lama semakin menghampiri batas punah. Salah satu spesies baru orangutan yang ditemukan pada tahun 2017 adalah orangutan tapanuli . Orangutan Tapanuli sebelumnya dianggap sebagai populasi orangutan paling selatan dari orangutan Tapanuli Namun berdasarkan penelitian secara mendalam oleh kelompok peneliti Indonesia dan mancanegara dalam bidang genetika, morfologi, ekologi, dan perilaku, ternyata Orangutan Tapanuli secara taksonomi malah lebih dekat dengan Orangutan Kalimantan (Pongo pygmaeus) sehingga harus dipisahkan menjadi spesies tersendiri. Penelitian juga mengindikasikan bahwa Orangutan Tapanuli merupakan moyang dari ketiga kera besar ini (Khoetiem dkk, 2014). Orangutan sangat lambat berkembangbiak: betina punya anak pertama di umur 15 tahun, dengan jarak antar melahirkan anak sekitar 8 atau 9 tahun, dan mereka terbagi dalam beberapa blok hutan yang saat ini terpisah. Maka penyambungan kembali populasi tersebut akan sangat penting untuk pelestarian dan untuk menghindari kawin silang (inbreeding). Jumlah populasi kecil ini berarti bahwa Orangutan Tapanuli adalah spesies kera besar yang paling langka dan paling terancam di dunia. Spesies khas Tapanuli ini sangat rentan terhadap gangguan sehingga seluruh sisa habitatnya perlu dilindungi, saat ini jumah orangutan tapanili sekitar 800 ekor. Orangutan sering dijadikan simbol dengan sebutan "umbrella species" yang memiliki makna penyeimbang ekosistem. (Muin, 2007). Ekosistem Batang Toru, yang juga disebut Harangan Tapanuli, dengan luas total sekitar 150.000 ha terletak di ketiga Kabupaten Tapanuli , Provinsi Tapanuli Utara. Dari luas tersebut, hampir 142.000 ha merupakan hutan primer yang tampak hijau tua di citra satelit di peta. Selebihnya adalah kawasan terdegradasi yang perlu direhabilitasi sekaligus membangun koridor antar blok-blok hutan yang telah terpisah. Sekitar $61,0 \%$ dari hutan primer terdapat di Kabupaten Tapanuli Utara, 29,7\% di Tapanuli Selatan, dan 9,3\% di Tapanuli Tengah. Berbagai upaya telah dilakukan untuk menjaga kelestarian orangutan. Salah satu caranya adalah mengembalikan habitat baru yang sesuai untuk kebutuhan orangutan, habitat orangutan pada umumnya berada di pohon. Pohon merupakan salah satu komponen terpenting bagi orangutan, pohon dapat dijadikan tempat untuk membangun sarangnya dikanopi. Orangutan membangun paling tidak satu sarang per hari. Orangutan dalam menyusun sarang memanfaatkan daun, ranting, liana sehingga identifikasi komposisi penyusun sarang orangutan sangat diperlukan.

\section{Perumusan Masalah}

Kelestarian orangutan berpengaruh terhadap keseimbangan ekosistem yang ada dihutan. Meskipun ada undang-undang dan lembaga yang bertanggung jawab untuk melindungi keberadaan orangutan, tetapi terus terjadi penurunan populasi orangutan akibat dari berbagai permasalahan yang terjadi seperti perburuan liar,perdagangan orangutansecara illegal, penebangan pohon secara liar yang menjadi habitat orangutan.

\section{Tujuan Penelitian}

Tujuan khusus penelitian ini adalah untuk melihat pohon yang sering dijadikan orangutan Tapanuli untuk bersarang, sehingga diperlukan upaya untuk menambah pohon yang sering dijadikan pohon sarang. Urgensi penelitian ini adalah orangutan Tapanuli adalah spesies baru orangutan yang baru ditemukan, sehingga diperlukan penelitian terbaru yang mendukung keberlangsungan hidup orangutan Tapanuli. 
Sijabat A, Sianipar Herna F, Simanullang Ady F : Topologi Sarang Orangutan Tapanuli (Pongo tapanuiliensis) di Hutan Batang Toru Kecamatan Sipirok Tapanuli Selatan

\section{Manfaat Penelitian}

Untuk mengetahui faktor yang mempengaruhi orangutan dalam membuat sarang, sehingga akan diperoleh informasi standarisasi orangutan dalam menyusun sarang.

\section{METODE PENELITIAN}

\section{Tempat dan Waktu Penelitian}

Hutan Batang Toru (HBT) memiliki luasan sekitar 136.000 ha dan terbagi dalam dua blok, yaitu blok Timur dan blok Barat. Secara administratif Hutan Batang Toru terletak di Kabupaten Tapanuli Utara, Tapanuli Tengah, dan Tapanuli Selatan, sedangkan secara geografis berada antara $98^{\circ} 53^{\prime}-99^{\circ} 26^{\prime}$ Bujur Timur dan $02^{\circ} 03^{\prime}-01^{\circ} 27^{\prime}$ Lintang Utara. Kawasan Hutan Batang Toru Blok Barat memiliki ketinggian mulai dari 50 mdpl sampai dengan 1875 mdpl. Titik terendahnya berada di Sungai Sihaporas (dekat kota Sibolga), dan titik tertingginya berada pada Dolok Lubuk Raya di bagian Selatan Kawasan Hutan Batang Toru. Kelerengan antara $16 \%$ sampai dengan lebih dari $60 \%$, bentuk medan di wilayah tersebut didominasi oleh bentuk topografi yang berbukit dan bergunung. Tanah di Hutan Batang Toru termasuk yang peka terhadap erosi.

\section{Alat dan Bahan Penelitian}

Alat yang dan bahan yang digunakan dalam penelitian ini adalah : Teropong Binocular Bushnell Powerview FOV 205 FT, Sony Digital Camera, Tali dengan panjang $25 \mathrm{~m}$, Meteran, GPS (Global Positioning System), Kompas.

\section{Prosedur Kerja}

1. Menggunakan line transek (transek garis lurus) untuk pengamatan. Data-data diambil dengan membuat line transek sebanyak 4 transek dengan titik pengamatan (Transek I,II,III,IV).

2. Ada 1 garis line transek dengan radius $900 \mathrm{~m}$ jarak lapang dengan titik yang ditentukan, dengan lebar $50 \mathrm{~m}$ kanan dan kiri . Tiap transek akan dilakukan pengamatan dengan cara berjalan kaki secara perlahan-lahan sambil melakukan pengamatan setiap pohon untuk melihat sarang.

3. Setelah ditemukan sarang, maka cara mengambil sampel tanaman penyusun sarang orangutan dari atas pohon adalah dengan memanjat pohon sarang, lalu diambil bagian tanaman yang dijadikan sebagai penyusun sarang orangutan Tapanuli (Pongo abelii). Setelah sampel didapat dimasukkan dalam plastik packing.

4. Kemudian dilakukan uji identifikasi tanaman penyusun sarang dengan bantuan buku identifikasi tanaman dengan penerbit Tjitrosoepomo, 2001; Van Steenis, 1978.

\section{Parameter Pengamatan}

Parameter pengamatan adalah Tanaman penyusun sarang, diameter sarang dan posisi sarang orangutan Tapanuli di Hutan Batang toru.

\section{HASIL DAN PEMBAHASAN}

\section{Tanaman Penyusun Sarang Orangutan Tapanuli}

Membuat sarang merupakan salah satu perilaku harian orangutan. Sarang yang dimaksud adalah tempat peristirahatan orangutan setelah melakukan aktifitas hariannya (Muin, 2007). Aktifitas harian adalah seluruh aktivitas orangutan yang berlangsung sejak meninggalkan sarang tidur pada pagi hari dan berakhir hingga masuk kembali kedalam sarang untuk bermalam (Van Schaik, 2006). Semua kera besar termasuk orangutan membangun sarang yang bisa dipergunakan baik untuk beristirahat pada siang maupun tidur pada malam hari 
Sijabat A, Sianipar Herna F, Simanullang Ady F : Topologi Sarang Orangutan Tapanuli (Pongo tapanuiliensis) di Hutan Batang Toru Kecamatan Sipirok Tapanuli Selatan

(Van Schaik et al, 1994). Sarang bagi orangutan juga dapat berfungsi sebagai tempat bermain bagi orangutan muda, tempat berlindung, melahirkan, melakukan kopulasi, dan aktivitas makan (Rijksen, 1978). Berdasarkan hasil wawancara dengan pemandu di lapangan, orangutan Tapanuli liar tidak memperbaiki sarang lama tetapi orangutan Tapanuli semi-liar memperbaiki sarang lama dengan menggunakan daun dan ranting yang segar untuk digunakan kembali. Kegiatan bersarang orangutan tapanuli meliputi: pematahan dan pelekukkan cabang-cabang pohon, dan mengambil daun dari pohon untuk menyusun sarang yang akan digunakan untuk istirahat (tidur), alas untuk tempat makan, dan melindungi tubuh untuk menahan hujan seperti yang terlihat pada gambar dibawah ini.

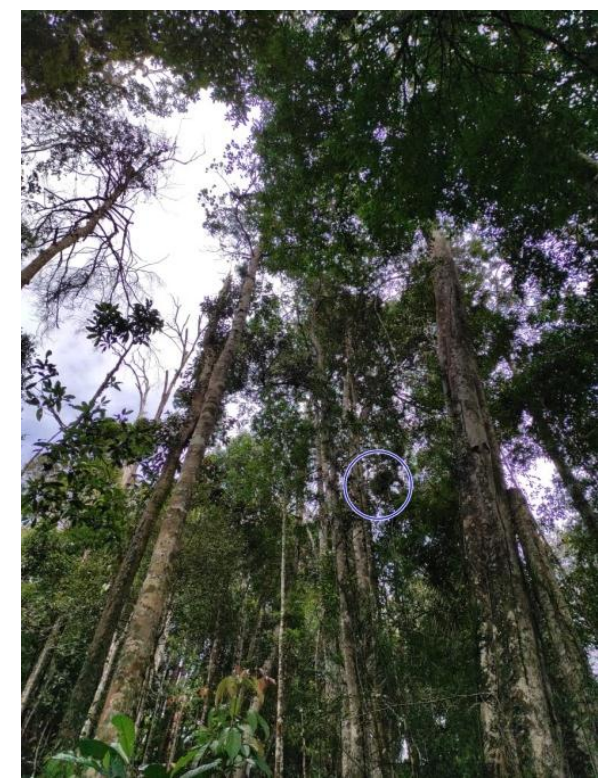

Gambar 1. Tanaman Penyusun Sarang Orangutan Tapanuli

Tanaman penyusun sarang orangutan Tapanuli adalah jenis tanaman yang digunakan oleh orangutan Tapanuli untuk menyusun sarang. Pada umumnya orangutan Tapanuli dalam menyusun sarang menggunakan jenis tanaman yang berasal dari pohon tempat bersarang. Tanaman penyusun sarang orangutan Tapanuli dapat dilihat pada tabel 1.

Tabel 1. Tanaman Penyusun Sarang Orangutan Tapanuli

\begin{tabular}{|l|l|l|l|}
\hline No & Nama Tanaman Penyusun Sarang & Jumlah & Persentase \\
\hline $\mathbf{1}$ & Medang (Litsea brachystachys) & 4 & 29 \\
\hline $\mathbf{2}$ & Hayun Dolok (Syzygium sp) & 6 & 43 \\
\hline $\mathbf{3}$ & Mayang (Palaquium gutta) & 2 & 14 \\
\hline $\mathbf{4}$ & Laccat bodat (Shorea hopeifolia). & 1 & 7 \\
\hline $\mathbf{5}$ & Hoteng (Quercus gemelliflora) & 1 & 7 \\
\hline Jumlah & $\mathbf{1 4}$ & $\mathbf{1 0 0}$ \\
\hline
\end{tabular}

Jumlah tanaman penyusun sarang orangutan Tapanuli yang dijumpai selama pengamatan adalah sebanyak 14 tanaman, yang terdiri dari 5 jenis tanaman. Jenis tanaman yang paling banyak digunakan sebagai tempatmembangun sarang adalah jenis Hayun dolok dalam bahasa lokal yaitu sebanyak 6 pohon (43\%). Hayun dolok dengan nama latin (Syzygium $s p$ ) dari famili Myrtaceae hal ini tidak lepas dari morfologi Syzygium sp. yang lebih sesuai dengan kebutuhan orangutan dalam membuat sarang. Dari hasil pengamatan di lapangan, pohon jenis ini memiliki tekstur kayu yang keras, tinggi mencapai $30 \mathrm{~m}$, banyak percabangan, dan daun yang tidak begitu rimbun. Jadi, orangutan di lokasi penelitian ini 
Sijabat A, Sianipar Herna F, Simanullang Ady F : Topologi Sarang Orangutan Tapanuli (Pongo tapanuiliensis) di Hutan Batang Toru Kecamatan Sipirok Tapanuli Selatan

cenderung untuk memilih pohon Syzygium sp. dibanding pohon lainnya. Kuswanda dan Sukmana (2005) menyatakan bahwa perilaku pemilihan bagian pohon sarang yang akan dijadikan tempat bersarang oleh orangutan, yaitu pada percabangan pohon.

\section{Diameter Sarang Orangutan Tapanuli}

Hasil yang didapat untuk diameter sarang dapat dilihat pada gambar 2 dibawah ini :

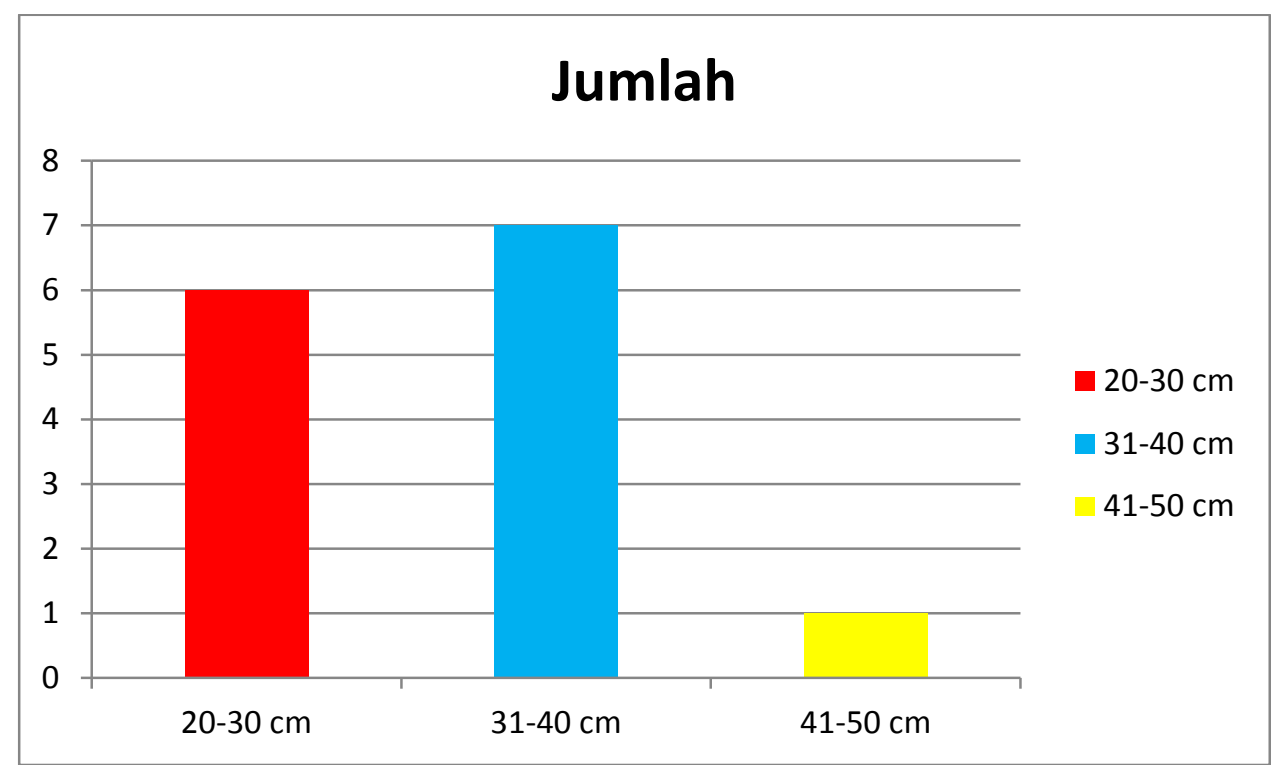

Gambar 2. Diameter Sarang Orangutan Tapanuli

Dari gambar 2 dapat dilihat bahwa diameter $31-40 \mathrm{~cm}$ mendominasi ukuran sarang orangutan Tapanuli, Hal ini dikarenakan berat orangutan Tapanuli berkisar 50-90 kg. Menurut Muin (2007), diameter sarang tidak mempunyai pengaruh yang penting bagi Orangutan Tapanuli,faktor diameter lebih bersifat dukungan kepada faktor jumlah jenis pakan dalam mempengaruhi keberadaan sarang pada pohon tertentu.

\section{Posisi Sarang Orangutan Tapanuli}

Kategori pembagian posisi sarang yaitu:

1. Posisi sarang $1=$ Terletak pada batang utama pohon

2. Posisi sarang 2 = Sarang berada di pertengahan atau dipinggir percabangan tanpa menggunakan pohon atau percabangan pohon dari pohon lainnya

3. Posisi sarang $3=$ Terletak pada pucuk pohon Posisi sarang

4. Posisi sarang $4=$ Posisi sarang yang terletak diantara dua pohon yang berbeda (Dalimunthe, 2009).

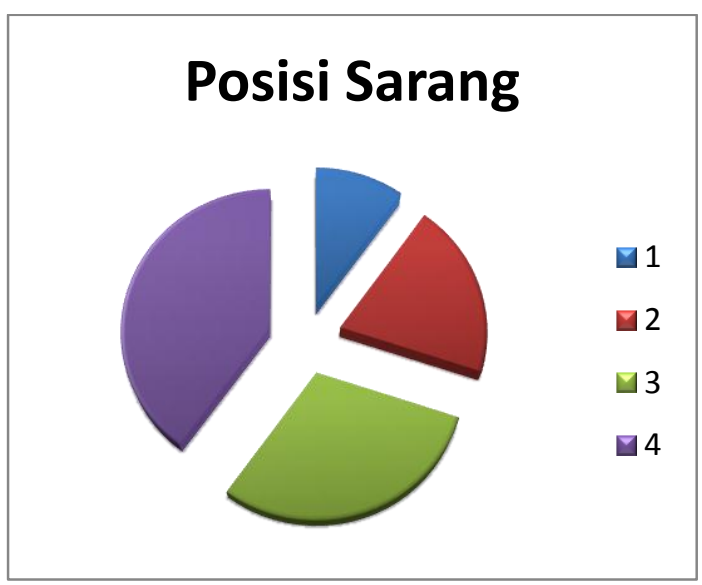


Sijabat A, Sianipar Herna F, Simanullang Ady F : Topologi Sarang Orangutan Tapanuli (Pongo tapanuiliensis) di Hutan Batang Toru Kecamatan Sipirok Tapanuli Selatan

Berdasarkan Gambar 4.8. diatas dapat diketahui bahwa posisi sarang paling dominan berada pada posisi 1 yaitu sebanyak sebanyak 43\%, posisi 2 yaitu $36 \%$, posisi 3 yaitu 14\% dan posisi 4 yaitu $7 \%$. Posisi sarang orangutan lebih banyak berada di batang utama pohon, karena orangutan Tapanuli menyukai batang pohon yang besar dan kuat.

\section{KESIMPULAN}

Berdasarkan hasil penelitian yang telah dilakukan dapat disimpulkan bahwa:

1. Jumlah tanaman penyusun sarang orangutan Tapanuli yang ditemukan sebanyak 14 sarang orangutan Tapanuli yang terdiri dari Hayun Dolok (Syzygium sp) 43\%, Medang (Litsea brachystachys) 29\%, Mayang (Palaquium gutta) 14\%, Laccat bodat (Shorea hopeifolia) 7\% dan Hoteng (Quercus gemelliflora) 7\%

2. Tanaman yang mendominasi adalah Hayun dolok

\section{DAFTAR PUSTAKA}

Khoetiem, M., I. Lovadi, dan A. Tjiu. 2014. Studi Awal Karakteristik Pohon Sarang dan Sarang Orangutan (Pongo pygmaeus pygmaeus: Linnaeus 1760). Protobiont 3 (2): 193- 200.

Kuswanda, W. 2013. Pendugaan Populasi Orangutan (Pongo abelii) Lesson 1827) Berdasarkan Sarang di Cagar Alam Sipirok, Tapanuli Utara. Jurnal Penelitian Hutan dan Konservasi Alam 10 (1): 19-31.

Muin, A., (2007), Analisis Tipologi Pohon Tempat Bersarang dan Karakteristik Sarang Orangutan (Pongo pygmaeus wurumbii Groves, 2001) Di Taman Nasional Tanjung Puting Kalimantan Tengah, Tesis, Kehutanan, Institut Pertanian Bogor.

Rahmi, Erdiansyah.Agustina D dan Jamin Faisal. 2014. Isolasi Dan Identifikasi Genus Salmonella Dan Shigella Dari Feses Orangutan Tapanuli (Pongo abelii) Di Pusat reintroduksi Orangutan, Jantho. Jurnal Medika Veterinaria ISSN : 0853-1943. Fakultas Kedokteran Hewan universitas Syiah Kuala, Banda Aceh

Rijksen, H.D., Meijaard, E., (1999), Diambang Kepunahan,The Gibbon Foundation Indonesia, Jakarta

S.A. Wich, I. Singleton M.G. Nowak, S.S. Utami,Atmoko, G. Nisam, S.M. Arif, R.H. Putra, R.Ardi, G. Fredikson, G. Usher, et al. 2016. Landcover changes predict steep declines for the Sumatran orangutan (Pongo abelii) Sci. Adv.,2,p.e1500789

Van Schaik, C., (1994), Diantara Orangutan Kera Merah Dan Bangkitnya Kebudayaan Manusia, Yayasan Penyelamatan Orangutan Borneo, Jakarta.

Van Steenis, C. G. J., (1978), Flora, Penerbit Pradnya paramitha, Jakarta Pusat

\begin{tabular}{|l|l|l|l|}
\hline Accepted Date & Revised Date & Decided Date & Accepted to Publish \\
\hline 26 Oktober 2020 & 28 Oktober 2020 & 03 November 2020 & Ya \\
\hline
\end{tabular}

